\title{
La inoculación con hongos endófitos entomopatógenos en semilla genera una respuesta fisiológica y promueve el crecimiento vegetal en plantas de chile poblano en invernadero \\ Inoculation with endophytic entomopathogenic fungi generates a physiological response and promotes plant growth in poblano pepper plants
}

Emmanuel Ortiz-Espinoza ${ }^{1}$, Fabiola Villegas-Rodríguez ${ }^{1}$, Hugo Magdaleno Ramírez-Tobías ${ }^{1}$, Luisa Eugenia del Socorro Hernández-Arteaga ${ }^{1}$ y José Marín-Sánchez ${ }^{1}$

Palabras clave: hongos endófitos; hongos entomopatógenos; inoculación en semilla; promoción de crecimiento vegetal; tasa de asimilación neta; cepas; procesos fisiológicos; San Luis Potosí; chile poblano; semillas; eficiencia; conductancia estomática; plantas Keywords: endophyte fungi; entomopathogen fungi; seed inoculation; plant growth promotion, net assimilation rate; strains; physiological processes; San Luis Potosi; poblano chili; seeds; efficiency; stomatal conductance; plants

Recibido en: 30-07-2020 / Aceptado en: 03-10-2020

\section{Resumen}

Introducción: Algunos hongos entomopatógenos actúan como endófitos y son promotores del crecimiento. Estos beneficios pueden ser explicados por mejoras en procesos fisiológicos. En esta investigación se evaluó el efecto de cepas comerciales de hongos endófitos entomopatógenos y de aislados de suelos agrícolas del estado de San Luis Potosí (HEE) sobre el crecimiento, fotosíntesis, intercambio de gases y producción en plantas de chile poblano, considerando el efecto del método de inoculación usado.

Metodología: Se usó como modelo al chile poblano (Capsicum annuum L.) cultivado bajo condiciones de laboratorio y en invernadero. Se evaluaron siete cepas de HEE: tres aislados de suelo agrícola de San Luis Potosí, pertenecientes a los géneros Metarhizium. (aislado RV01), Paecilomyces. (RV05) y Penicillium (aislado SL14); dos cepas de los hongos entomopatógenos Beauveria bassiana [(Bals.-Criv.) Vuill. 1992] (aislado BB42) y Metarhizium anisopliae [(Metschn.) Sorokin 1883)] (aislado MA25) aisladas de insectos y dos cepas comerciales de $B$. bassiana (aislado BB09) y M. anisopliae (aislado MA28). Se preparó una solución de conidios y se probaron dos métodos: 1) inoculación en semilla; y 2) aspersión del sustrato y una segunda aplicación cuando emergió la primera hoja verdadera. Se incluyeron testigos en cada experimento (se inoculo agua y un agente surfactante). Se evaluaron parámetros fotosintéticos (eficiencia máxima y efectiva de PSII, disipación fotoquímica y no fotoquímica, tasa de transporte de electrones), intercambio de gases (tasa de asimilación neta, conductancia estomática y ${ }^{1}$ Universidad Autónoma de San Luis Potosí, Facultad de Agronomía y Veterinaria. E-mail: hugo.ramirez@uaslp.mx; phdeoe110788@gmail.com

(C) Universidad De La Salle Bajío (México) 
transpiración) y el porcentaje de colonización en hoja, tallo y raíces. Al final del experimento se midió la longitud de la raíz, biomasa seca total, de la parte aérea de la planta y de la raíz.

Resultados: A los 33 días después de la inoculación se observó como la inoculación con RV01, MA25, BB09 y SL14 aumentaron la asimilación neta de $\mathrm{CO}_{2}$ y la conductancia estomática, respecto a los testigos, al ser inoculados por semilla o por aspersión. Inocular directamente las semillas con HEE mejoró significativamente la asimilación de $\mathrm{CO}_{2}$, la disipación fotoquímica y la eficiencia efectiva de PSII en comparación con plantas inoculadas por aspersión. El aislado RV05 sobresalió por los resultados observados en el invernadero, con mayor producción de biomasa total. Las plantas inoculadas por semilla mostraron un aumento en la producción de biomasa total, y en el peso seco de la parte aérea y de raíces con respecto a las plantas inoculadas por aspersión. Un mayor crecimiento en las plantas se asoció con la colonización endófita.

Conclusiones: Los HEE aislados a partir de suelos agrícolas de San Luis Potosí pueden competir con cepas comerciales en la promoción del crecimiento de plantas de chile poblano en invernadero. La inoculación directa de HEE sobre la semilla genera mejores resultados, aunque con variaciones en función de la cepa.

\begin{abstract}
Introduction: Some entomopathogenic fungi act as endophytes and promote plant growth. Such benefits can be explained by improvements in physiological processes. In this research, the effect of commercial strains of entomopathogenic endophytic fungi and isolates from agricultural soils of San Luis Potosi on growth, photosynthesis, gas exchange and production in poblano chili plants was evaluated, considering the effect of the inoculation method used.

Methodology: Poblano chili plants (Capsicum annuum L.) was used as a model which was sown under controlled conditions and in a greenhouse. Seven HEE strains were evaluated: three native isolates from agricultural soils of San Luis Potosi that by their characteristics belong to the genus Metarhizium (RV01 strain), Paecilomyces (RV05 strain) and Penicillium (SL14 strain); two strains isolated from insects, Beauveria bassiana [(Bals.-Criv.) Vuill. 1992] (BB42 strain) and Metarhizium anisopliae [(Metschn.) Sorokin 1883) (MA25 strain) and two commercial strains of B. bassiana (BB09 strain) and M. anisopliae (MA25 strain). A conidial solution was prepared, and two methods were tested: 1) seed inoculation; and 2) substrate spraying and a second application when the first true leaf emerged. Controls were included in each treatment (water and the surfactant
\end{abstract}


were inoculated). Photosynthetic parameters (maximum and effective efficiency of PSII, photochemical and non-photochemical dissipation, electron transfer rate), gas exchange parameters (net assimilation rate, stomatal conductance, and transpiration) and colonization percentage of steam, leaf and root were evaluated during the experiment. At the end of the experiment total dried biomass, dry weight of the aerial part of the plant and the root, and root length was measured.

Results: At 33 days after inoculation it was observed how inoculation with RV01, MA25, BB09 and SL14 increased $\mathrm{CO}_{2}$ assimilation and stomatal conductance, with respect to controls, when inoculated by seed or by spraying. Inoculation directly over the seed significantly improved $\mathrm{CO}_{2}$ assimilation, photochemical quenching, and effective efficiency of PSII comparing to plants inoculated by foliar spraying. The isolate RV05 stood out due to the results observed in the greenhouse, with a higher total biomass production. The plants inoculated by seed showed an increase in the production of total biomass, and in the dry weight of the aerial part and roots with respect to the plants inoculated by aspersion. Greater growth in plants was associated with endophytic colonization.

Conclusion: HEE isolated from agricultural soils of San Luis Potosi can compete with commercial strains in promoting growth in poblano chili plants in greenhouse. Direct seed inoculation of endophytic entomopathogenic fungi generated better results, although with variations depending on the strain.

\section{Introducción}

El chile (Capsicum spp.) es una hortaliza perteneciente a la familia de las solanáceas, originaria de América y cultivado en todo el mundo, con innumerables usos como producto fresco, seco y procesado (Dubey et al., 2019). Sin embargo, la incidencia de plagas, así como eventos climáticos extremos son los causantes de considerables pérdidas en el rendimiento de ciertas variedades de chile (Joukhadar y Walker, 2019). En los últimos 20 años, el crecimiento en producción fue hasta de un 35\%, siendo México el segundo mayor productor con 3.5 millones de toneladas (FAOSTAT, 2017), a pesar de considerables pérdidas en el rendimiento a causa del estrés biótico y abiótico (Lesk et al., 2016). Para erradicar estas problemáticas, se están buscando diferentes enfoques, destacando los sistemas de producción basados en el uso de microorganismos benéficos, usados en 
países como Turquía, que son un modelo de transición hacia prácticas agrícolas sustentables en un futuro, con la ventaja de disminuir el uso de plaguicidas (Dogan et al., 2016).

Los hongos entomopatógenos son ampliamente usados en el control biológico de insectos plaga y fitopatógenos del suelo (Jaber y Ownley, 2018). Pero además de su uso en el biocontrol, muchos hongos entomopatógenos actúan como endófitos, colonizando tejidos de la planta sin causar un daño aparente, promoviendo el crecimiento vegetal, mejorando la productividad y la vitalidad de la planta (Geisen et al., 2017; Hiruma et al., 2016; Hyde y Soytong, 2008; Raya-Díaz et al., 2017). Este aumento en el crecimiento se explica por las relaciones simbióticas entre los hongos endófitos y sus hospederos, que desencadenan modificaciones en procesos fisiológicos como la eficiencia en la fotosíntesis, el intercambio de gases, así como una mejor distribución de la energía (Rozpądek et al., 2015). En referencia al cultivo de papa, la aplicación de hongos endófitos entomopatógenos (HEE) en el tubérculo-semilla aumentó la fotosíntesis y el contenido de nutrientes en suelos sin adición de fertilizantes (Krell et al., 2018). La inoculación artificial de HEE en etapas tempranas del cultivo supera muchas limitantes comparado con la aplicación convencional de hongos entomopatógenos, pero algunos autores sugieren hacer aplicaciones repetidas del mismo HEE y así mejorar la colonización endófita (Jaber y Ownley, 2018). Existe evidencia que sugiere que la mejor forma de inocular los HEE es desde la semilla, lo que aduce a la importancia del método de inoculación. El tipo de método por el cual se inoculan los HEE es determinante en el nivel de promoción de crecimiento vegetal y en otras propiedades que confieren en plantas, como la protección contra insectos y patógenos de plantas, aunque hasta la fecha no existe un consenso al respecto (Jaber y Enkerli, 2016; Mckinnon et al., 2016; Vidal y Jaber, 2015).

Investigaciones recientes donde se probaron cuatro aislados de HEE (BB42, BB09, MA28 y MA25) han demostrado su capacidad de reducir la población de Bactericera cockerelli (Sulc) (Hemiptera: Triozidae) en invernadero, un insecto plaga y un importante vector de enfermedades en el estado de San Luis Potosí, México (Villegas-Rodríguez et al., 2017). Estos cuatro aislados tienen además la capacidad de promover el crecimiento vegetal en etapas tempranas, aunque en los ensayos in vitro no se encontraron diferencias significativas, los ensayos en maceta sugieren que el aislado MA28 tuvo mayor efecto en el crecimiento de chile poblano (Ortiz-Espinoza et al., 2019). Lo señalado anteriormente, hizo formular el objetivo de esta investigación, que fue evaluar el efecto de las cuatro cepas de HEE mencionadas sobre plantas de chile poblano a nivel fotosintético y de crecimiento, durante las primeras etapas de desarrollo en laboratorio y en 
invernadero, comparando su efecto con tres nuevas cepas aisladas de suelos agrícolas del estado de San Luis Potosí y con un testigo, y comparando por igual el efecto cuando el HEE es inoculado en semilla o por aspersión. Lo anterior considerando como hipótesis que todas las cepas son promotoras activas del mejoramiento de procesos fisiológicos en las etapas más avanzadas del cultivo.

\section{Materiales y Métodos}

\section{Aislados de hongos entomopatógenos y endófitos}

En este ensayo se evaluaron 7 cepas de HEE: tres aislados nativos de San Luís Potosí (RV01, RV05, SL14) donados por el laboratorio de fitopatología de la Facultad de Agronomía y Veterinaria de la Universidad Autónoma de San Luis Potosí; dos cepas que fueron aisladas de insectos, una corresponde a Beauveria bassiana (BB42) [(Bals. -Criv.) Vuill. 1912] y otra a Metarhizium anisopliae (MA25) [(Metschn.) Shotokan 1883]; finalmente, se probaron dos ingredientes activos de productos comerciales, la cepa de B. bassiana (BB09) del producto Bassianil MR BioTropic y otra cepa de M. anisopliae (MA28) del producto Meta - Bichs ${ }^{\circledR}$, BioBichs ${ }^{\circledR}$. Los últimos cuatro aislados fueron donados por el Laboratorio de Reproducción de Organismos Benéficos del Comité Estatal de Sanidad Vegetal del Estado de Guanajuato, México (CESAVEG) (Villegas-Rodríguez et al., 2014).

Las tres cepas nativas de San Luis Potosí fueron aisladas de suelos agrícolas, utilizando al insecto trampa Tenebrio molitor (gusano de la harina) (Ríos-Velasco et al., 2014). De acuerdo con sus características morfológicas y macroscópicas, se propone que el aislado RV01, pertenece al género Metarhizium, el cual presentó conidios cilíndricos hialinos, con bordes redondeados y característica de coloración verde oliva al observarse en el microscopio óptico (40X) (Sepúlveda et al., 2016); el aislado RV05, por su parte, presentó similitud con el género Paecilomyces, en el cual se observaron conidióforos cortos, paredes lisas, hialino, no ramificado, y se observaron fiálides producidos en ramas cortas en hifas, consistentes en fiálides individuales que nacen irregularmente en hifas aéreas (Paul et al., 2013). Por último, el aislado SL14 presentó características morfológicas asociadas al género Penicillium, como lo son conidios globosos y conidióforos densamente peniciliados, conidióforos hialinos, ramificados peniciliadamente en los ápices con métula primaria y secundaria, formando cabezas conidiales de color verde amarillento bastantes separadas (Rothen et al., 2017). Cada uno de los cultivos monospóricos se sembró en 
Agar Dextrosa Sabouraud (BD Bioxon®) suplementado con 5\% de extracto de levadura, y se incubaron a $25 \pm 1^{\circ} \mathrm{C}$, de una a dos semanas, hasta que se presentó esporulación (VillegasRodríguez et al., 2017).

\section{Cultivo de chile poblano en laboratorio y en invernadero}

El experimento se realizó en los meses de agosto a diciembre de 2018 utilizando como modelo el cultivo de chile poblano (Capsicum annuиm L.). Las semillas fueron donadas por productores de chile poblano del municipio de Mexquitic de Carmona, San Luis Potosí. Se evaluaron dos métodos de inoculación de HEE: el primer método consistió en desinfectar superficialmente las semillas de chile poblano con una solución de hipoclorito de sodio al 10\% $(\mathrm{NaOCl})$ durante 10 minutos, después se realizó un lavado con etanol al 70\% por un minuto, y finalmente se realizaron cinco lavados con agua destilada estéril (Behie et al., 2017). Se utilizó un testigo, el cual consistió en sumergir las semillas en una solución al 0.2\% de INEX-A® $\left(\right.$ COSMOCEL $\left.^{\circledR}\right)$, y para el resto de los tratamientos se prepararon $10 \mathrm{ml}$ de una solución de conidios e INEX-A® (COSMOCEL®) al $0.2 \%$, con una concentración final de $1 \times 10^{8}$ esporas $\mathrm{ml}^{-1}$, y una viabilidad de más del $90 \%$. Se sembraron 50 semillas por cada tratamiento en semilleros de poliestireno expandido de 200 cavidades rellenas del sustrato comercial Peat moss (Premier Horticulture, Quakertown, PA) (Akello y Sikora, 2012). En el segundo método de inoculación, después de sembrar 400 semillas (50 por cada tratamiento y el testigo), se realizó la aspersión del sustrato con la solución de conidios y se repitió la inoculación por aspersión en toda la planta después del surgimiento de la primera hoja verdadera (Tall y Meyling, 2018).

Las plantas se mantuvieron en condiciones de laboratorio en semilleros de poliestireno expandido después de su germinación a una temperatura de 25 a $28{ }^{\circ} \mathrm{C}$, con una humedad relativa del 60 al 80\% y un fotoperiodo de 16:8 horas (Luz: Oscuridad) proporcionado con lámparas de 32 Watts (Phillips $®$ ). A los 51 días después de la inoculación (ddi) se trasplantaron 5 plantas por tratamiento en bolsas de polietileno de 5 litros de capacidad usando la mezcla de sustrato BM2, Berger®. El experimento se ejecutó en un invernadero de baja tecnología, tipo túnel ubicado en el campo agrícola experimental de la Facultad de Agronomía y Veterinaria de la Universidad Autónoma de San Luis Potosí. Desde el trasplante hasta la finalización del cultivo se aplicó fertilización de manera semanal, ajustándose a las necesidades del cultivo (Orellana y León, 2011). 


\section{Evaluación del efecto de inoculación con HEE en el intercambio de gases}

Los parámetros de intercambio de gases y de fluorescencia de la clorofila se registraron con un sistema portátil para la medición de fotosíntesis LI-6400XT (Licor, Inc.; NE, EE. UU), analizando cinco plantas por tratamiento, seleccionando una hoja con un desarrollo pleno al momento de la medición, la cual fue la misma en los 3 análisis realizados. Las variables de intercambio de gases fueron: tasa de asimilación neta ( $\mu$ mol $\mathrm{CO}_{2} \mathrm{~m}^{-2} \mathrm{~s}^{-1}$ ), transpiración $\left(\mathrm{mmol} \mathrm{H} \mathrm{H}_{2} \mathrm{O}^{-2} \mathrm{~s}^{-1}\right) \mathrm{y}$ conductancia estomática ( $\mathrm{mol} \mathrm{H}_{2} \mathrm{O} \mathrm{m}^{-2} \mathrm{~s}^{-1}$ ). La primera medición se realizó en condiciones de laboratorio a los $33 \mathrm{ddi}$, con una temperatura promedio de $31^{\circ} \mathrm{C}$ y un nivel de radiación fotosintéticamente activa (RFA) de $100 \mu \mathrm{mol} \mathrm{m} \mathrm{m}^{-2} \mathrm{~s}^{-1}$ proporcionado por el equipo de medición (Mantzoukas et al., 2015). En la etapa de invernadero se realizaron otras dos mediciones, una a los 86 ddi y la otra a los 116 ddi con un nivel de RFA de $800 \mu \mathrm{mol} \mathrm{m} \mathrm{m}^{-2} \mathrm{~s}^{-1}$ y $900 \mu \mathrm{mol} \mathrm{m}^{-2} \mathrm{~s}^{-1}$. Los valores de RFA referidos se decidieron con base en el registro de RFA sobre las plantas al momento de cada medición y para que la radiación fuera constante para todas las plantas durante la misma.

\section{Evaluación del efecto de inoculación con HEE parámetros relacionados con la fluorescencia de la clorofila}

Los parámetros de fluorescencia de la clorofila registrados fueron: fluorescencia mínima (Fo) en oscuridad de una hoja, que posteriormente se sometió por pocos segundos a una luz roja lejana para forzar la migración de electrones entre el fotosistema I (PSI) y el fotosistema II (PSII) (Buchanan, et al., 2015). De esta manera se estimó la eficiencia efectiva del PSII ( $\phi$ PSII) y la eficiencia máxima de PSII $\left(\mathrm{F}_{\mathrm{v}} / \mathrm{F}_{\mathrm{m}}\right)$ [la fluorescencia variable $(\mathrm{Fv})$ es la diferencia de la fluorescencia máxima $(\mathrm{Fm})$ respecto de la fluorescencia mínima (Fo), dividido entre el valor de la fluorescencia máxima (Fm) (García-Cristóbal et al., 2015)]. Además, con pulsos de luz saturada cada $20 \mathrm{~s}$ se calculó la disipación fotoquímica (qP), y la disipación no fotoquímica (NPQ y qN) y la tasa transporte de electrones (ETR) después de la aplicación de una serie de pulsos de saturación bajo irradiación actínica creciente (Li et al., 2007; Kalaji et al., 2014). Las mediciones se realizaron a los 44, 87 y $117 \mathrm{ddi}$, analizando cinco plantas por tratamiento. 


\section{Evaluación de la promoción del crecimiento vegetal}

Al finalizar el experimento (121 ddi), se midió la longitud de la raíz y se registró además el peso seco de la parte aérea y de la raíz por separado, sumándose para obtener el valor de la producción de biomasa total (Khan et al., 2015).

\section{Porcentaje de colonización}

Se evaluó el porcentaje de colonización en hoja, tallo y raíz de plantas inoculadas con hongos endófitos por tratamiento a los 28, 45 y 120 ddi. Se evaluaron dos plantas por tratamiento a los 28 y 45 ddi, y tres plantas por tratamiento a los 120 ddi. Para cada análisis se extrajeron las plantas, se lavaron adecuadamente, se separaron en tallo, hojas y raíces y con un bisturí se obtuvieron 5 secciones para los análisis realizados a los 28 ddi y 45 ddi (con dos plantas por tratamiento), 10 secciones para los análisis realizados a los 121 ddi (con tres plantas por tratamiento). Las secciones de tejido de cada tratamiento se colocaron en cajas Petri, y se desinfectaron superficialmente con solución de hipoclorito de sodio al 5\% ( $\mathrm{NaClO}$ ) durante 20 minutos. Después se realizó un lavado con etanol al 70\% durante un minuto y finalmente se realizaron cinco lavados con agua destilada estéril. Posteriormente se secaron en una campana de flujo laminar (excluyendo la epidermis) y se colocaron las diferentes secciones en cajas Petri con Agar Dextrosa Sabouraud (BD Bioxon®), suplementado con $5 \%$ de extracto de levadura, se incubaron durante siete a diez días a $25 \pm 1^{\circ} \mathrm{C}$, monitoreando diariamente el crecimiento micelar y observando en el microscopio, comprobando que corresponda a la morfología del HEE inoculado y confirmando que son endófitos (Parsa et al., 2013). Como un control de desinfección, se inocularon $10 \mu \mathrm{l}$ del líquido remanente del proceso de desinfección. Los datos se expresaron como porcentaje de colonización, donde el porcentaje de colonización $=100 \times$ (número de piezas de plantas colonizadas/número total de piezas de plantas analizadas) (Gurulingappa et al., 2010).

\section{Análisis Estadístico}

Los experimentos se llevaron a cabo según un diseño completamente al azar. Los datos se analizaron de acuerdo con un arreglo factorial de tratamientos en donde se consideraron los efectos simples y combinados de los aislados de HEE (BB09, BB42, MA25, MA28, RV01, RV05, SL14 y un testigo inoculado solamente con INEX-A) y los métodos de inoculación [Inoculación en Semilla (IS) e inoculación por aspersión en el sustrato y en la primera hoja verdadera (IA)]. Las 
variables de fluorescencia de la clorofila, intercambio de gases, producción de biomasa y longitud de la raíz analizaron mediante análisis de varianza (ANAVA) con arreglo factorial y el porcentaje de colonización con ANAVA de medidas repetidas. Cuando se encontraron efectos estadísticamente significativos se realizó la comparación de medias con la prueba de Dunnett con un $\alpha=0.05$ en función de que las comparaciones de medias se propusieron con respecto a un testigo y a que se ha señalado que es eficiente en reducir el error, en comparación con las pruebas de Tukey

y Duncan (Sauder y DeMars, 2019). En todos los análisis se utilizó el software SAS versión 9 (SAS Institute Inc., 2002). Los datos de $\mathrm{F}_{\mathrm{v}} / \mathrm{F}_{\mathrm{m}}, \mathrm{qP}$ y qN a los 87 ddi se transformaron con la función de coseno para normalizar los datos.

\section{$\underline{\text { Resultados }}$}

\section{Evaluación del intercambio de gases}

A los 33 ddi, cuando las plantas se mantuvieron en condiciones de laboratorio, se encontró un efecto significativo de la cepa (HEE, $\mathrm{p}=0.002)$ sobre la tasa de asimilación neta, la conductancia estomática y la transpiración (Tabla 1). A los 86 y 116 ddi no se encontraron diferencias significativas entre las variables evaluadas (Tabla 1). Además, existió una interacción significativa entre los factores HEE y método de inoculación sobre la tasa de asimilación neta y la transpiración ( $\mathrm{p}<0.005$ HEE*MI, Tabla 1), observando que algunas cepas aumentan estas variables, y que este efecto es dependiente del método de inoculación empleado (Figs. 1A y 1C).

La inoculación promovió el aumento de la tasa de asimilación neta, aunque sólo para algunos aislados y con dependencia del método de inoculación. A los 33 ddi, la inoculación por semilla con los aislados MA25, RV01 y SL14 promediaron $3.9 \mu \mathrm{mol} \mathrm{CO} 2 \mathrm{~m}^{-2} \mathrm{~s}^{-1}$, valor mayor al de las plantas testigo. Mientras que, en plantas inoculadas por aspersión, el aislado BB09 y el RV01 fueron los inóculos que aumentaron la tasa de asimilación neta con respecto al testigo ( $\mathrm{p}=0.002$ HEE*MI; Fig. 1A). A pesar de que a los 86 ddi no se encontraron efectos estadísticamente significativos en la tasa de asimilación neta entre las cepas de HEE y los MI evaluados, la interacción entre ambos factores sí resultó significativa $(\mathrm{p}=0.020)$. A los 86 ddi se observó un aumentó en la tasa de asimilación neta en comparación con el testigo en las plantas inoculadas desde semilla con el aislado RV05 y en las inoculadas por aspersión con MA28 (Fig. 1D).

La conductancia estomática varió significativamente por efecto de la inoculación solamente con una de las 7 cepas evaluadas, RV01. A los 33 ddi, la inoculación por aspersión con el aislado 
La inoculación con hongos endófitos entomopatógenos en semilla genera una respuesta fisiológica y promueve el crecimiento vegetal en plantas de chile poblano en invernadero

RV01 aumentó significativamente ( $\mathrm{p}=0.011 \mathrm{HEE}$; Fig. 1B) la conductancia estomática (0.077 mol $\left.\mathrm{H}_{2} \mathrm{O} \mathrm{m}^{-2} \mathrm{~s}^{-1}\right)$ en comparación con el testigo $\left(0.034 \mathrm{~mol} \mathrm{H}_{2} \mathrm{O} \mathrm{m}^{-2} \mathrm{~s}^{-1}\right)$. La inoculación con las cepas distintas de RV01 por cualquiera de los métodos evaluados fue poco relevante sobre la conductancia estomática.

Tabla 1. Resultados de los análisis de varianza de las variables de intercambio de gases en condiciones controladas, a los 33 días después de la inoculación y en condiciones de invernadero (86 y 116 días después de la inoculación) de plantas de chile poblano inoculadas comparando dos métodos de inoculación (MI) y diferentes aislados de hongos entomopatógenos y endófitos (HEE).

Table 1. Results of the analysis of variance of the gas exchange variables under controlled conditions at 33 days after inoculation, and in greenhouse conditions (86 and 116 days after inoculation) of poblano chili plants comparing two inoculation methods (MI) and different entomopathogenic and endophytic fungi (HEE).

\begin{tabular}{|c|c|c|c|c|c|c|c|c|c|c|}
\hline \multirow[t]{2}{*}{ Tiempo } & \multirow{2}{*}{$\begin{array}{c}\text { Fuente } \\
\text { de } \\
\text { variación }\end{array}$} & \multicolumn{3}{|c|}{$\begin{array}{c}\text { Tasa de } \\
\text { asimilación neta } \\
\left(\text { umol } \mathrm{CO}^{2} \mathrm{~m}^{-2} \mathrm{~s}^{-1}\right)\end{array}$} & \multicolumn{3}{|c|}{$\begin{array}{l}\text { Conductancia estomática } \\
\qquad\left(\mathrm{mol} \mathrm{H}_{2} \mathrm{O} \mathrm{m}^{-2} \mathrm{~s}^{-1}\right)\end{array}$} & \multicolumn{3}{|c|}{$\begin{array}{c}\text { Transpiración } \\
\left(\mathrm{mmol} \mathrm{H}_{2} \mathrm{O} \mathrm{m}^{-2} \mathrm{~s}^{-1}\right)\end{array}$} \\
\hline & & GL & $\mathbf{F}$ & p & GL & F & $\mathbf{p}$ & GL & $\mathbf{F}$ & p \\
\hline \multirow{3}{*}{33 ddi } & MI & 1 & 2.42 & 0.128 & 1 & 0.03 & 0.871 & 1 & 0.22 & 0.040 \\
\hline & HEE & 7 & 4.00 & 0.002 & 7 & 3.13 & 0.011 & 7 & 3.37 & 0.007 \\
\hline & HEE*MI & 7 & 3.51 & 0.005 & 7 & 1.71 & 0.136 & 7 & 2.39 & 0.040 \\
\hline \multirow{3}{*}{86 ddi } & MI & 1 & 2.95 & 0.074 & 1 & 0.88 & 0.353 & 1 & 0.02 & 0.897 \\
\hline & HEE & 7 & 1.9 & 0.091 & 7 & 1.87 & 0.089 & 7 & 1.09 & 0.381 \\
\hline & HEE*MI & 7 & 2.60 & 0.020 & 7 & 1.01 & 0.432 & 7 & 0.76 & 0.622 \\
\hline \multirow{3}{*}{116 ddi } & MI & 1 & 0.33 & 0.565 & 1 & 0.88 & 0.35 & 1 & 0.15 & 0.704 \\
\hline & HEE & 7 & 0.71 & 0.665 & 7 & 1.87 & 0.08 & 7 & 1.38 & 0.288 \\
\hline & HEE*MI & 7 & 0.91 & 0.505 & 7 & 1.01 & 0.43 & 7 & 1.01 & 0.432 \\
\hline
\end{tabular}

HEE: Hongo endófito entomopatógeno; MI: Método de inoculación; ddi: días después de la inoculación; GL: Grados de libertad. Los valores $\mathbf{F}$ y $\mathbf{p}$ se obtuvieron en el análisis de varianza.

HEE: Endophytic entomopathogenic fungi; MI: inoculation method; ddi: days after inoculation; GL: Degrees of freedom. $\mathbf{F}$ and $\mathbf{p}$ values were obtained in the analysis of variance.

La inoculación causó disminución de la transpiración cuando se realizó en la semilla con 5 de las 7 cepas evaluadas, pero no cuando se realizó por aspersión. Este efecto solo se observó a los 33 ddi (HEE*MI p=0.020). A los 86 y 166 ddi no se registró efecto significativo de la inoculación sobre la transpiración. A los 33 ddi la inoculación por semilla con los aislados BB09, BB42, MA28, RV05 y SL14 redujo hasta la mitad la transpiración en comparación con el testigo. ( $\mathrm{p}=0.040$ HEE*MI, Fig. 1C). La inoculación por aspersión no generó cambios significativos en la transpiración (Fig. 1C). 


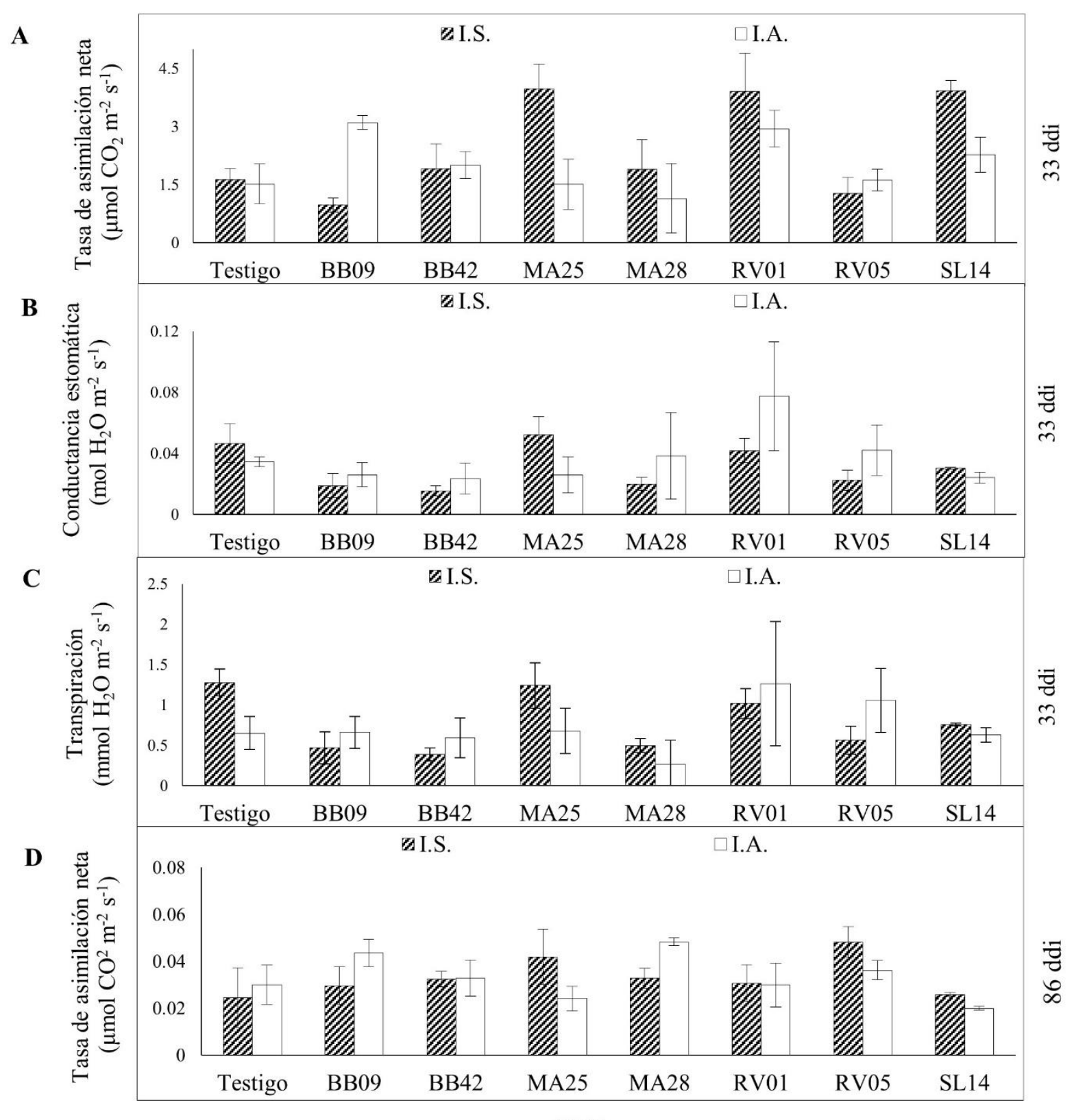

HEE

Fig. 1. Tasa de asimilación neta, conductancia estomática y transpiración en plantas de chile poblano inoculadas con hongos endófitos entomopatógenos (HEE) desde semilla (I.S.) y por aspersión en sustrato y en la primera hoja verdadera (I.A.).

Testigo: inoculación con una solución de INEX-A ® al 0.02\%; ddi: días después de la inoculación; las barras de error representan el error estándar.

Fig. 1. Net assimilation rate of $\mathrm{CO} 2$, stomatal conductance, and transpiration in poblano chili plants inoculated with endophytic and entomopathogenic fungi (HEE) from seed (I.S.) and by spraying on the substrate and on first true leaf (I.A.).

Control: inoculation with a $0.02 \%$ solution of INEX-A ${ }^{\circledR}$; ddi: days after inoculation; error bars represent standard error. 
Tabla 2. Análisis de varianza para evaluar el efecto de dos métodos de inoculación (MI) y de diferentes aislados de hongos endófitos entomopatógenos (HEE) en parámetros de

fluorescencia de la clorofila medidos en plantas de chile poblano a los 44, 87 y 117 días después de la inoculación.

Table 2. Analysis of variance to evaluate the effect of two inoculation method (MI) and different entomopathogenic and endophytic fungi isolates (HEE) on chlorophyll fluorescence parameters measured in poblano chili plants at 44, 87 and 117 ddi.

\begin{tabular}{|c|c|c|c|c|c|c|c|c|c|c|c|c|c|c|}
\hline \multirow{2}{*}{ Tiempo } & \multirow{2}{*}{$\begin{array}{l}\text { Factor de } \\
\text { variación }\end{array}$} & \multicolumn{3}{|c|}{$\mathbf{F}_{\mathrm{v}} / \mathbf{F}_{\mathrm{m}}$} & \multicolumn{2}{|c|}{$\phi_{\text {PSII }}$} & \multicolumn{2}{|c|}{$\mathbf{q} \mathbf{P}$} & \multicolumn{2}{|r|}{$\mathbf{q N}$} & \multicolumn{2}{|c|}{ NPQ } & \multicolumn{2}{|c|}{$\begin{array}{c}\text { ETR } \\
\left(\mu \mathrm{molm}{ }^{-2} \mathrm{~s}^{-1}\right)\end{array}$} \\
\hline & & GL & F & $\mathbf{p}$ & F & $\mathbf{p}$ & F & $\mathbf{p}$ & F & $\mathbf{p}$ & F & p & $\mathbf{F}$ & p \\
\hline \multirow{3}{*}{$44 \mathrm{ddi}$} & MI & 1 & 0.00 & 9542 & 4.56 & 0.0 & 0.08 & 0.7852 & 2.22 & 0.1455 & 0.97 & 0.3318 & 0.65 & 0.4266 \\
\hline & HEE & 7 & 1.27 & 0.2963 & 1.09 & 0.3938 & 3.31 & 0.0088 & 1.67 & 0.1520 & 1.33 & 0.2674 & 1.50 & 0.2027 \\
\hline & $\mathrm{HEE}^{*} \mathrm{MI}$ & 7 & 1.61 & 0.1674 & 2.95 & 0.0164 & 1.08 & 0.3959 & 2.24 & 0.0557 & 1.57 & 0.1784 & 1.70 & 0.1433 \\
\hline \multirow{3}{*}{$87 \mathrm{ddi}$} & & 1 & 2.66 & 0.1122 & 10.66 & 0.0026 & 7.29 & 0.0134 & 0.35 & 0.5554 & 0.11 & 0.7372 & 3.45 & 0.0723 \\
\hline & HEE & 7 & 3.24 & 0.0099 & 1.59 & 0.1719 & 1.22 & 0.3177 & 0.95 & 0.4832 & 1.12 & 0.3749 & 1.43 & 0.2270 \\
\hline & HEE*MI & 7 & 1.92 & 0.0975 & 0.70 & 0.6744 & 0.70 & 0.6688 & 0.47 & 0.8505 & 0.21 & 0.9814 & 1.85 & 0.1111 \\
\hline \multirow{3}{*}{117 ddi } & $\mathrm{HE}$ & 1 & 0.20 & 0.658 & 0.22 & 0.6402 & 0.49 & 0.4880 & 0.46 & 0.5009 & 0.57 & 0.4560 & 0.44 & 0.5097 \\
\hline & MI & 7 & 1.70 & 0.1542 & 1.51 & 0.1985 & 0.97 & 0.4668 & 1.39 & 0.2419 & 1.17 & 0.3478 & 1.37 & 0.2508 \\
\hline & HEE*MI & 7 & 0.88 & 0.1435 & 1.10 & 0.3838 & 0.79 & 0.602 & 0.45 & 0.8589 & 1.01 & 0.4408 & 0.79 & 0.6009 \\
\hline
\end{tabular}

Fv/Fm: Eficiencia máxima del PSII; $\phi$ PSII: Eficiencia efectiva de PSII; qP: Disipación fotoquímica; qN y NPQ: Disipación no fotoquímica; ETR: Tasa de transporte de electrones; GL: Grados de libertad. Los valores de $\mathbf{F}$ y $\mathbf{p}$ se obtuvieron del análisis de varianza; ddi: Días después de la inoculación.

Fv/Fm: Maximum efficiency of the PSII; $\phi$ PSII: Effective efficiency of PSII; qP: Photochemical quenching; qN and NPQ: Non-photochemical quenching; ETR: Electron transport rate; GL: Degrees of freedom. The values of $\mathbf{F}$ and $\mathbf{p}$ were obtained from the analysis of variance; ddi: Days after inoculation.

\section{Evaluación de la fluorescencia de la clorofila}

Considerando el umbral de significación estadística de 0.05 , a los 44 y $87 \mathrm{ddi}$, tres de los seis parámetros de fluorescencia de la clorofila resultaron afectados por el método de inoculación y/o por el aislado de HEE (Fv/Fm, фPSII y qP), aunque se encontró una interacción significativa sólo sobre $\phi_{\text {PSII a los }} 44$ ddi (Tabla 2). La cepa RV01 provocó una disminución de un 11\% de la Fv/Fm en relación con el valor registrado por el testigo, a los 87 ddi (HEE, p=0.0099, Tabla 2). La inoculación por semilla provocó aumentos significativos con respecto a la inoculación por aspersión, en la $\phi_{\text {PSII }}$, un $8 \%$ a los 44 ddi y un $23 \%$ a los 87 ddi, y la qP, un 14\% a los 87 ddi (Tabla 3). A los 117 ddi, ninguna variable de fluorescencia de la clorofila resultó afectada significativamente (Tabla 2). 
Tabla 3. Parámetros de fluorescencia de la clorofila medidos en plantas de chile poblano inoculadas con dos métodos distintos y con diferentes aislados de hongos entomopatógenos a los 44 y 87 días después de inoculación.

Table 3. Chlorophyll fluorescence parameters measured in poblano chili plants inoculated with two different methods and different isolates of entomopathogenic fungi at 44 and 87 days after inoculation.

\begin{tabular}{|c|c|c|c|c|c|c|}
\hline Tratamiento & Fv/Fm & $\phi P S I I$ & $\mathbf{q P}$ & $\mathbf{q N}$ & NPQ & $\underset{\left(\mu \mathrm{mol} \mathrm{m}{ }^{-2} \mathrm{~s}^{-1}\right)}{\mathbf{E T R}}$ \\
\hline Testigo & 0.7716 & 0.2553 & 0.5311 & 0.7575 & 1.5197 & 11.1954 \\
\hline BB09 & 0.7787 & 0.2512 & 0.5226 & 0.7601 & 1.5249 & 10.9826 \\
\hline BB42 & 0.7884 & 0.2450 & 0.5058 & 0.7692 & 1.6248 & 10.7355 \\
\hline MA25 & 0.7848 & 0.2321 & 0.4488 & 0.7361 & 1.4056 & 9.7974 \\
\hline MA28 & 0.7841 & 0.2437 & 0.4906 & 0.7443 & 1.4770 & 10.8354 \\
\hline RV01 & 0.7938 & 0.2211 & 0.4420 & 0.7363 & 1.4221 & 9.7820 \\
\hline RV05 & 0.7873 & 0.2340 & 0.4152 & 0.7321 & 1.3839 & 9.3011 \\
\hline SL14 & 0.7745 & 0.2500 & 0.5114 & 0.7363 & 1.3999 & 10.9368 \\
\hline I.S. & 0.7824 & $0.2513 *$ & 0.4839 & 0.7398 & 1.4364 & 10.5941 \\
\hline I.A. & 0.7834 & 0.2318 & 0.4829 & 0.7535 & 1.5031 & 10.2974 \\
\hline Testigo & 0.6671 & 0.1892 & 0.5911 & 0.8797 & 2.0476 & 72.5128 \\
\hline BB09 & 0.65338 & 0.1864 & 0.5897 & 0.8545 & 1.8532 & 73.1762 \\
\hline BB42 & 0.6990 & 0.1846 & 0.5903 & 0.8700 & 2.0087 & 73.2403 \\
\hline MA25 & 0.6935 & 0.2018 & 0.6366 & 0.8482 & 1.7927 & 83.1870 \\
\hline MA28 & 0.6946 & 0.1648 & 0.5174 & 0.8610 & 1.9889 & 71.1979 \\
\hline RV01 & 0.5913 & 0.1317 & 0.4736 & 0.8549 & 1.7597 & 53.5992 \\
\hline RV05 & 0.6943 & 0.1620 & 0.5481 & 0.8728 & 2.0281 & 77.7084 \\
\hline SL14 & 0.6562 & 0.1625 & 0.5487 & 0.8683 & 1.9571 & 71.0264 \\
\hline I.S. & 0.6808 & $0.1909 *$ & $0.5984 *$ & 0.8612 & 1.9209 & 75.5306 \\
\hline I.A. & 06565 & 0.1548 & 0.5255 & 0.8661 & 1.9381 & 68.3815 \\
\hline
\end{tabular}

Fv/Fm: Eficiencia máxima del fotosistema II (PSII); $\phi$ PSII: Eficiencia efectiva de PSII; qP: Disipación fotoquímica; qN y NPQ: Disipación no fotoquímica; ETR: Tasa de transporte de electrones; ddi: Días después de la inoculación. El símbolo $(*)$ indica diferencia estadística significativa de acuerdo con la prueba de Dunnett $(\mathrm{p} \leq 0.05)$ al comparar de manera independiente del efecto de los HEE es con respecto al testigo y el efecto del método de inoculación; en este último caso el * se colocó en el valor mayor cuando la prueba de comparación de medias resultó significativa.

Fv/Fm: Maximum efficiency of photosystem II (PSII); $\boldsymbol{\phi P S I I}$ : Effective efficiency of PSII; qP: Photochemical quenching; qN and NPQ: Non-photochemical quenching; ETR: Electron transport rate; ddi: Days after inoculation. Symbol (*) indicate a significant statistical difference according to Dunnett test $(\mathrm{p} \leq 0.05)$ when independently comparing HEE effect with respect to control; and inoculation method effect, in the latter case, * was placed at the highest value when mean comparison test was significant. 
La inoculación promovió el incremento significativo de la $\phi$ PSII cuando se realizó por semilla, pero promovió un decremento en esa variable cuando se hizo por aspersión. El incremento se registró con los aislados BB09, BB42, MA25, MA28 y RV05, con valores hasta 30\% mayores que el testigo en las plantas inoculadas por semilla a los 44 ddi. En contraste, la inoculación por aspersión con las cepas BB42, MA25, MA28, RV01 y RV05 promovió la reducción de la фPSII (Tabla 2; Fig. 2).

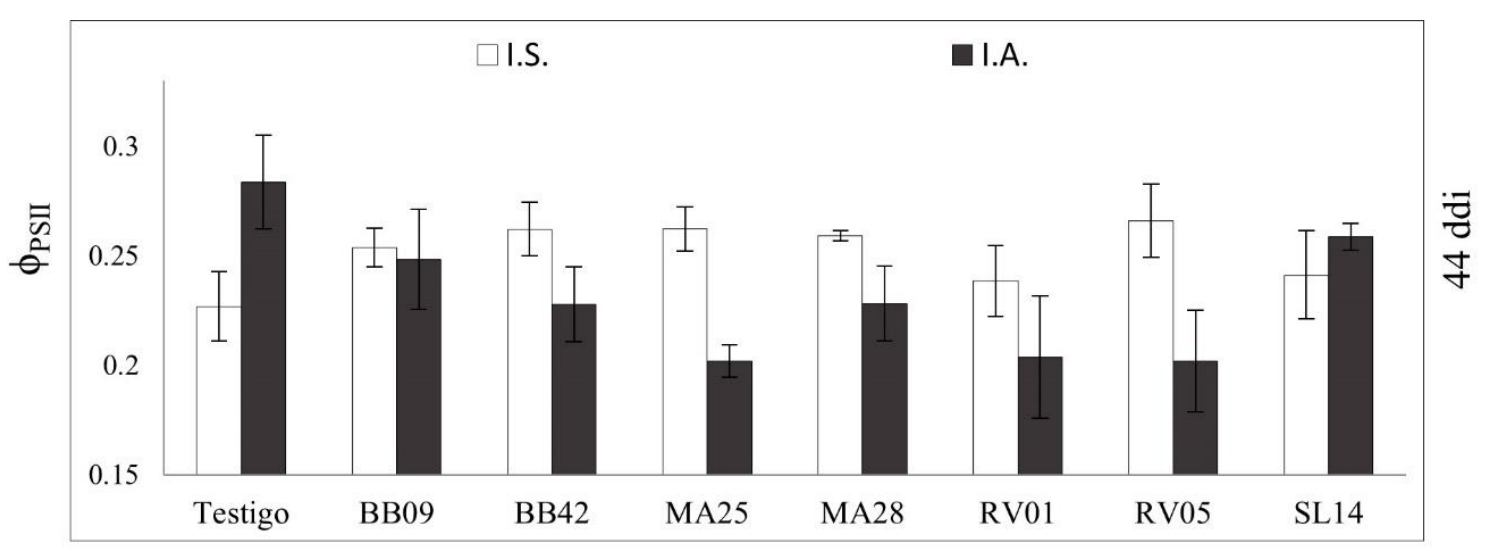

HEE

Fig. 2. Efecto del método de inoculación y de diferentes aislados de hongos endófitos entomopatógenos en la eficiencia máxima del PSII $\left(\phi_{\mathrm{PSII}}\right)$ a los 44 ddi.

I.S.: Inoculación en semilla; I.A.: Inoculación por aspersión; ddi: Días después de la inoculación. Las barras de error representan el error estándar.

Fig. 2. Effect of inoculation method and of different isolates of endophytic entomopathogenic fungi on the maximum efficiency of PSII ( $\phi$ PSII) and on nonphotochemical quenching ( $\mathrm{qN})$ at 44 ddi.

I.S.: Seed inoculation; I.A.: Spray inoculation; ddi: Days after inoculation. The error bars represent the standard error.

\section{Evaluación del crecimiento de plantas}

Las variables de crecimiento fueron afectadas tanto por el método de inoculación como por la cepa de HEE. Las plantas que fueron inoculadas por semilla aumentaron el peso seco de la parte aérea de la planta, un $20 \%$ con respecto a las plantas inoculadas por aspersión ( $\mathrm{p}<0.05)$, mientras que en la producción de biomasa total el aumento fue de un $18 \%$ ( $\mathrm{p}<0.05$ ). La inoculación con el aislado RV05 superó en más de un tercio el peso seco de la parte aérea $(\mathrm{p}<0.05)$ y casi duplicó la biomasa total con respecto al testigo $(\mathrm{p}<0.05)$. La inoculación con el aislado RV01 casi duplicó el peso seco de la raíz en comparación con el testigo. La inoculación por aspersión favoreció el incremento de la longitud de la raíz (Tabla 4). 
Tabla 4. Atributos de crecimiento de plantas de chile poblano inoculadas con hongos entomopatógenos con dos métodos luego de 121 días de experimentación.

Table 4. Growth attributes of poblano chili plants inoculated with entomopathogenic fungi with two methods after 121 days of experimentation.

\begin{tabular}{|c|c|c|c|c|}
\hline FV & $\begin{array}{c}\text { Peso seco } \\
\text { parte aérea (mg. } \\
\left.\text { planta }^{-1}\right)\end{array}$ & 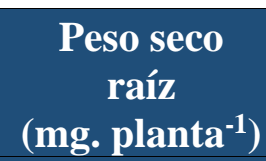 & $\begin{array}{l}\text { Biomasa total } \\
\left(\mathrm{mg}^{\text {planta }}{ }^{-1}\right)\end{array}$ & $\begin{array}{c}\text { Longitud } \\
\text { de la raíz }(\mathrm{cm})\end{array}$ \\
\hline \multicolumn{5}{|c|}{ HEE } \\
\hline Testigo & $2.14 \pm 0.21$ & $0.5974 \pm 0.05$ & $2.74 \pm 0.03$ & $13.05 \pm 1.09$ \\
\hline BB09 & $2.46 \pm 0.18$ & $0.8096 \pm 0.07$ & $3.27 \pm 0.04$ & $17.43 \pm 1.04$ \\
\hline BB42 & $2.31 \pm 0.22$ & $0.7894 \pm 0.08$ & $3.10 \pm 0.05$ & $17.07 \pm 1.09$ \\
\hline MA25 & $2.58 \pm 0.15$ & $0.6447 \pm 0.02$ & $3.23 \pm 0.01$ & $14.32 \pm 1.07$ \\
\hline MA28 & $2.64 \pm 0.29$ & $0.7545 \pm 0.10$ & $3.39 \pm 0.05$ & 17. $10 \pm 0.91$ \\
\hline RV01 & $2.79 \pm 0.37$ & $0.95 \pm 0.13$ & $3.75 \pm 0.07$ & $16.36 \pm 1.10$ \\
\hline RV05 & $3.30 \pm 0.33 *$ & $0.74 \pm 0.05$ & $4.04 \pm 0.03 *$ & $13.59 \pm 0.92$ \\
\hline SL14 & $2.01 \pm 0.29$ & $0.57 \pm 0.07$ & $2.58 \pm 0.04$ & $15.65 \pm 1.19$ \\
\hline \multicolumn{5}{|c|}{ MI } \\
\hline I.S. & $2.81 \pm 0.13 *$ & $0.78 \pm 0.04 *$ & $3.60 \pm 0.16 *$ & $15.22 \pm 0.54$ \\
\hline I.A. & $2.24 \pm 0.13$ & $0.68 \pm 0.04$ & $2.93 \pm 0.15$ & $15.91 \pm 0.57^{*}$ \\
\hline \multicolumn{5}{|c|}{ Resultados del ANA VA (valores de p) } \\
\hline $\mathrm{HEE}$ & 0.0159 & 0.0799 & 0.018 & 0.3303 \\
\hline MI & 0.0016 & 0.0335 & 0.0171 & 0.0090 \\
\hline $\mathrm{HEE}^{*} \mathrm{MI}$ & 0.1195 & 0.4604 & 0.1390 & 0.0271 \\
\hline $\mathrm{EE}$ & 0.1004 & 0.0310 & 0.1196 & 0.4001 \\
\hline
\end{tabular}

El símbolo * indica diferencias estadísticamente significativas en la comparación de medias con la prueba de Dunnett $(\mathrm{p} \leq 0.05)$. EE: Error estándar.

Symbol * indicate statistically significant differences in the comparison of means with the Dunnett test $(\mathrm{p} \leq 0.05)$. EE: Standard error.

El MI interactuó de manera significativa con la cepa de HEE sobre la longitud de raíz (p = 0.0271) (Fig. 3). Las plantas inoculadas por aspersión con las cepas BB09, BB42 y MA28 desarrollaron raíces un $21 \%, 17 \%$ y $16 \%$ mayores que el testigo, similares a la longitud registrada en raíces de aquellas que fueron inoculadas en semilla con la cepa RV01 (Fig. 3). 


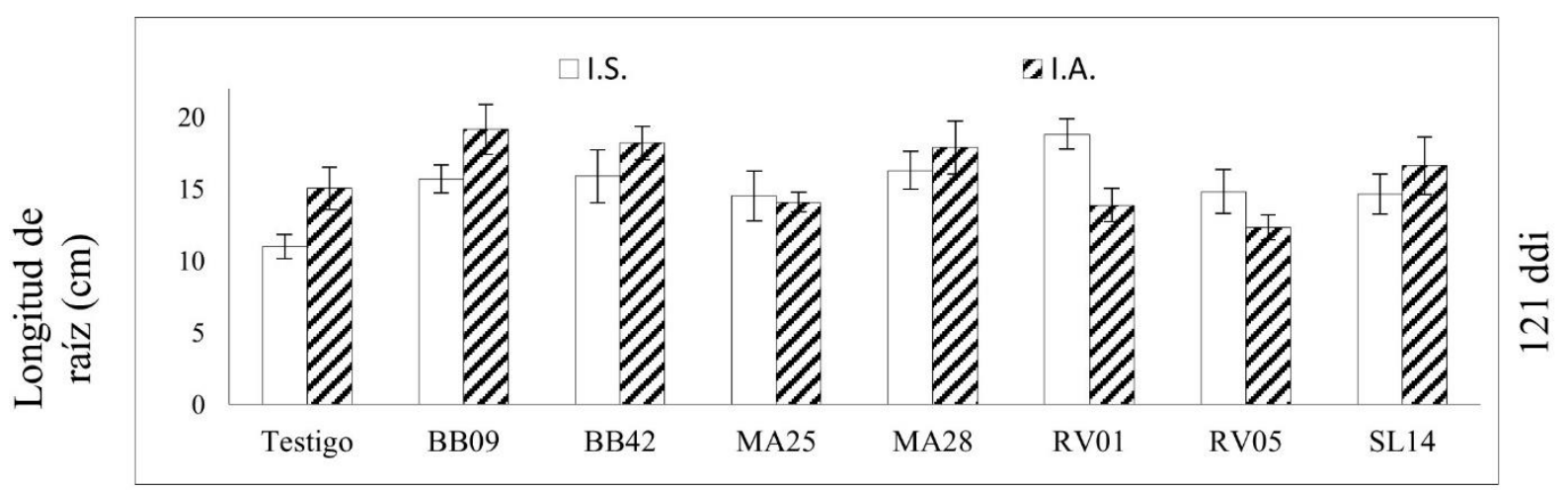

HEE

Fig. 3. Efecto del método de inoculación y de diferentes aislados de hongos endófitos entomopatógenos en la longitud de la raíz a los 121 ddi.

I.S.: Inoculación en semilla; I.A.: Inoculación por aspersión; ddi: Días después de la inoculación. Las barras de error representan el error estándar.

Fig. 3. Effect of the inoculation method and of different isolates of endophytic entomopathogenic fungi on root length at $121 \mathrm{ddi}$.

I.S.: Seed inoculation; I.A.: Spray inoculation; ddi: Days after inoculation. The error bars represent the standard error.

\section{Porcentaje de colonización}

Independientemente de la cepa de HEE, la inoculación por semilla en promedio duplicó la colonización de hoja, tallo y raíz en comparación con la inoculación por aspersión. No obstante, se registraron variaciones que dependieron de la cepa de HEE inoculada. Los aislados RV05, RV01 y BB42 generaron mayores porcentajes de colonización, que fueron hasta cinco o diez veces más que los alcanzados por BB09, MA25 y SL14.

Las cepas RV05 y BB42 se encontraron de manera más frecuente en hoja, tallo y raíz, que los otros aislados, principalmente al ser inoculadas en la semilla (Fig. 4). El aislado RV05 se encontró en todos los tejidos evaluados, con porcentajes de colonización que alcanzaron 100\% en raíz a los 28 ddi al inocularse en semilla, y de un $40 \%$ a los 121 ddi, y, además, fue el aislado que se detectó mayormente en tallo, con un $100 \%$ de colonización al inocularse en semilla, y de $40 \%$ al inocularse por aspersión a los 28 ddi (Fig. 4). Cuando fue inoculado en la semilla, el aislado RV01 se detectó en raíz con un 50\% de colonización a los 45 ddi y en hoja a los 28 y 45 ddi con 10\% de colonización (Fig. 4A y C). El mismo aislado, RV01, solamente se encontró en la hoja cuando fue inoculado por aspersión, con un nivel de colonización de 40\% (Fig. 4A). El aislado BB42 se encontró en hoja, raíz y tallo, aunque fue más frecuente al ser inoculado en la semilla que al ser inoculado por aspersión, con niveles de colonización de hasta 50\% (Fig. 4). 
Ortiz-Espinoza, E. et al.

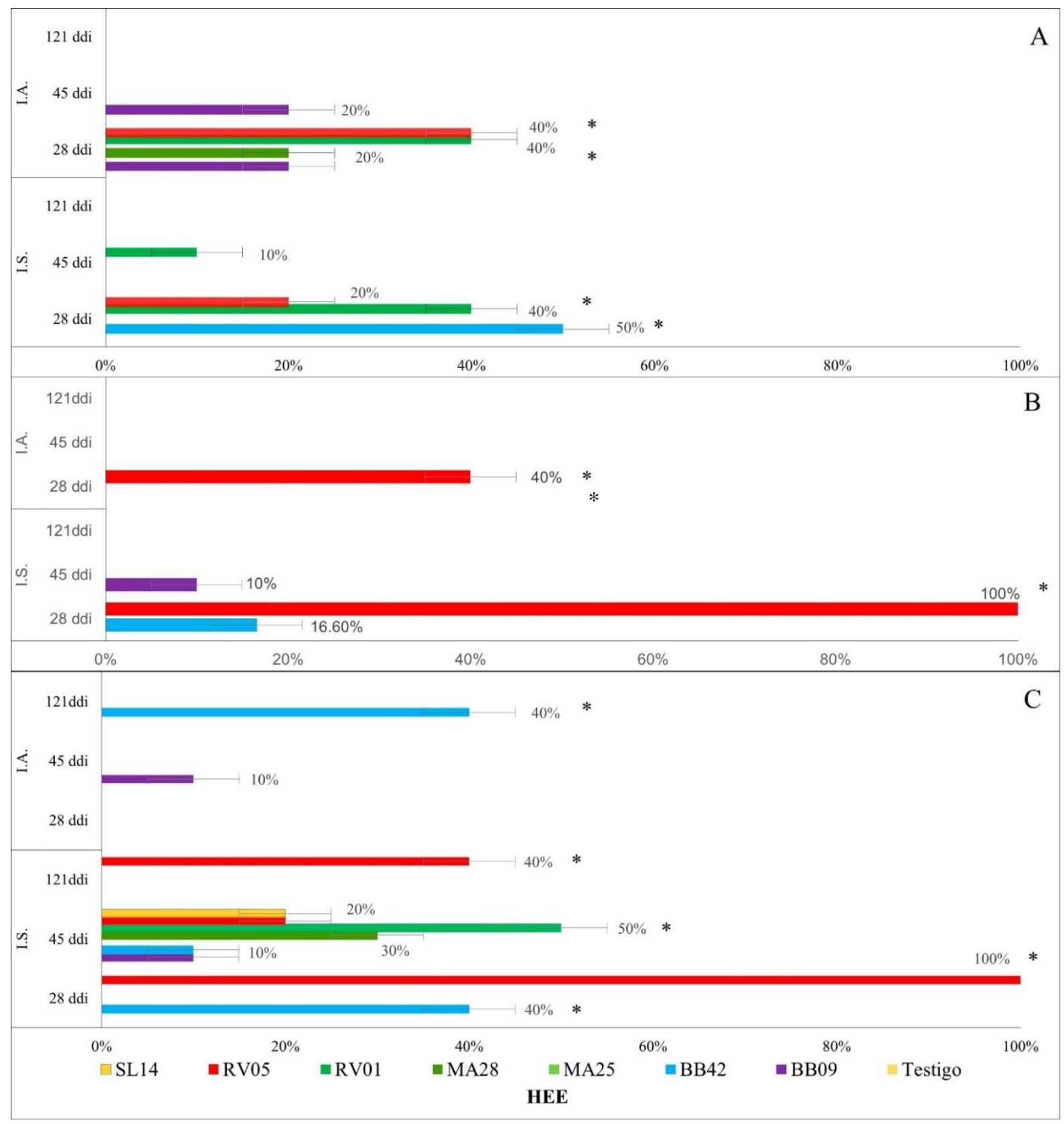

Fig. 4. Efecto del método de inoculación y de diferentes cepas de HEE en el porcentaje de colonización en hojas (A), tallos (B) y raíces (C) en plantas de chile poblano a los 28, 45 y

121 días después de inoculación (ddi).

I.S.: Inoculación en semilla; I.A.: Inoculación por aspersión en sustrato y en la primera hoja verdadera. Las barras de error representan el error estándar. Se realizó una prueba de Dunnett con un $\alpha$

$$
=0.05, \mathrm{p} \leq 0.0001 \text {. }
$$

Fig. 4. Effect of the inoculation method and of different HEE strains on the percentage of colonization in leaves (above), stems (medium) and roots (below) in poblano chili plants at 28, 45 and 121 days after inoculation (ddi).

I.S.: Seed inoculation; I.A.: Inoculation by aspersion in substrate and in the first true leaf. The error bars represent the standard error. Dunnett's test was performed with an $\alpha=0.05, \mathrm{p} \leq 0.0001$. 
El aislado BB09 alcanzó porcentajes de colonización de $20 \%$ en la hoja cuando se inoculó por aspersión (Fig. 4A) y en un 10\% en la raíz con ambos métodos de inoculación evaluados (Fig. 4C); no obstante, en tallo solo se observó la presencia del hongo cuando la inoculación se realizó en semilla (Fig. 4B). El aislado MA25, por su parte, sólo se encontró en la hoja al ser inoculado por aspersión (Fig. 4A) mientras que SL14 sólo se encontró en la raíz, pero al ser inoculado en la semilla (Fig. 4C).

\section{Discusión}

\section{Efectos de la inoculación con HEE en el intercambio de gases y en la fluorescencia de la clorofila en plantas de chile poblano}

Los resultados de esta investigación apoyan la hipótesis de que algunas cepas de HEE promueven el mejoramiento funcional en las plantas de chile, en variables como la tasa de asimilación neta, conductancia estomática y transpiración, como se registró a los 33ddi (Fig. 1).

Se observó un aumento en los parámetros fisiológicos de las variables analizadas durante la primera etapa del experimento. El efecto más sobresaliente fue el aumento en la tasa de asimilación neta de las plantas inoculadas por semilla con los aislados RV01, MA25 y SL14 (Fig. 1A, HEE $\mathrm{p}=0.005$ ). En cuanto a las plantas inoculadas por aspersión, sobresalen las cepas BB09 y RV01, aumentando la tasa de asimilación neta. Una mayor asimilación neta de $\mathrm{CO}_{2}$ puede considerarse una forma de soportar la elevada demanda de energía, que podría alterar sustancialmente el rendimiento fotosintético, al igual que otras variables como la conductancia estomática (Centritto et al., 2009). A los 33 ddi la cepa RV01 inoculada por aspersión aumentó la conductancia estomática ( $\mathrm{p}=0.011$, Fig. 1B) y la transpiración ( $\mathrm{p}=0.007$, Fig. 1C). Este aumento podría beneficiar a la planta, ya que un aumento en estos parámetros favorece la absorción de nutrientes minerales y de microelementos (Cho et al., 2008). Mejorar las propiedades fotosintéticas podría conducir a un uso más eficiente de la energía obtenida de la luz, así como a una mayor asimilación del carbono en el ciclo de Calvin (Kramer y Evans, 2011). Existen antecedentes donde la colonización por hongos endófitos interviene en la regulación de proteínas relacionadas con la fotosíntesis y en la respuesta de la planta a estrés al exceso de luz o la sequia (Gómez-Vidal et al., 2006; Ghaffari et al., 2018).

En este trabajo se encontró un efecto en algunas de las variables de fluorescencia de clorofila a causa del método de inoculación (Tabla 2). En las mediciones realizadas a los 87 ddi, 
en invernadero, fue evidente un aumento de la фPSII en las plantas inoculadas desde semilla, en comparación con las plantas inoculadas por aspersión (Tabla 3), aunque no todas las cepas de HEE promovieron esta respuesta (Fig. 2). En otros cultivos inoculados desde semilla, como la papa, la inoculación con Metarhizium brunneum aumentó la $\mathrm{F}_{\mathrm{v}} / \mathrm{F}_{\mathrm{m}}$ y la psiI, al igual que la conductancia estomática, la tasa de asimilación neta, la biomasa y el contenido de macroelementos como nitrógeno y fosforo (Krell et al., 2018). Otros organismos benéficos, como las bacterias del género Bacillus han demostrado efectos similares en plantas de chile habanero al aumentar parámetros como qP, ETR y Fv/Fm (Samaniego-Gámez et al., 2016). Estos mismos autores documentaron la reducción de la transpiración, lo que coincide con nuestros resultados. Por otro lado, en otros modelos como el sorgo dulce (Sorghum bicolor) inoculado por aspersión con B. bassiana, M. robertsii e Isaria fumosorosea, no se encontró un efecto en el contenido de clorofila, en la transpiración y en la fotosíntesis (Mantzoukas et al., 2015), aunque en el trabajo solo se aplicó un método de inoculación.

\section{Efectos de la inoculación de HEE en la producción de biomasa de chile poblano}

Se registró un alto porcentaje de colonización en plantas inoculadas con el aislado RV05 (Fig. 4), factor que pudo influir en el aumento significativo en la producción de biomasa, en comparación el testigo sin inocular (Tabla 4). Esta cepa presenta similitud en su morfología con aislados del género Paecilomyces, que también son endófitos en chile (Paul et al., 2013)

Los resultados de este trabajo muestran que los aislados BB42, BB09 y MA28 aumentaron significativamente la longitud de la raíz en comparación con el testigo cuando son inoculados por aspersión (Tabla 4 y Fig. 3). Es probable que el aumento en la longitud de raíces ocurriera en las primeras etapas de crecimiento, como fue comprobado en un estudio previo en donde se documentó que la longitud de la raíz de las plantas inoculadas con los aislados MA28 y BB42 aumentó hasta tres veces más que el testigo a los 45 ddi (Ortiz-Espinoza et al., 2019). Cabe señalar que las mayores longitudes de raíz se registraron en las plantas inoculadas por aspersión con las cepas de B. bassiana (BB09 y BB42) y de M. anisopliae (MA28) pero este efecto no se reflejó en el aumento del peso seco de la raíz, evaluada al finalizar el experimento, en cambio, el crecimiento registrado en raíces de plantas inoculadas con el aislado RV01 desde semilla, aumento tanto la longitud de la raíz como el peso seco final de la raíz (Tabla 4). La promoción de crecimiento en raíces inducido por la inoculación con Metarhizium anisopliae está respaldada por otros autores (García et al., 2011; 
Sasan y Bidochka, 2012; Bamisile et al., 2018). Anteriormente se observó un aumento en la longitud de plántulas de chile poblano en estudios in vitro con la cepa BB42 (Ortiz-Espinoza et al., 2019), pero este efecto no ocurre en ensayos en invernadero. B. bassiana como endófito tiene un amplio rango de hospederos, y es sumamente efectivo en colonizar las plantas cuando es asperjado en las hojas, como pudimos comprobarlo en los ensayos de endofitismo (Fig. 4), sin embargo, en los parámetros fisiológicos estudiados el efecto de la inoculación de B. bassiana no fue significativo, aunque se comprobó que otras cepas tienen capacidad de promover el crecimiento vegetal e inducir proteínas relacionadas con la fotosíntesis y el metabolismo energético (Jaber y Enkerli, 2016; Mckinnon et al., 2016; Tall y Meyling, 2018).

\section{Efecto del método de inoculación en el porcentaje de colonización}

Se han probado diferentes técnicas para inocular artificialmente HEE en cultivos. La técnica de aspersión sobresale como la metodología más aplicada y exitosa, en comparación con otras técnicas como la aplicación en raíces directamente o la inoculación directa en semilla (Bamisile et al., 2018). Sin embargo, esto contrasta con los resultados obtenidos en este trabajo, y con muchos otros reportes que resaltan las cualidades de la técnica de inoculación en semilla como la mejor técnica para introducir HEE artificialmente en cultivos agrícolas, demostrando efectos antagónicos contra hongos fitopatógenos, asi como una reducción del efecto causado por insectos plaga, ya sea por competencia de espacio y nutrientes o bien, por la induccion de respuestas de defensa de la planta (Quesada-Moraga et al., 2009; Gurulingappa et al., 2010; Akello y Sikora, 2012; Akutse et al., 2013; Greenfield et al., 2016).

La inoculación en la semilla promovió un mayor porcentaje de colonización en tallo, hojas y raices en comparación con el método de aspersión, como fue evidente en las plantas inoculadas con el aislado RV05, principalmente en tallo y en raíz (Fig. 4A). Muchos HEE han demostrado altos índices de colonización en plantas de diferentes familias, con variaciones no solo en función de la cepa, sino también en cuanto al órgano donde fue aislado, y sobre todo con el tiempo en que el endofitismo fue detectado (Ownley et al., 2008; Akutse et al., 2013; Castillo-Lopez et al, 2014). En este trabajo, las cepas locales mostraron mayor capacidad de colonización que el resto de las cepas evaluadas (Fig. 4), y estos aislados fueron los mayores promotores del crecimiento vegetal en chile poblano (Tabla 4). Los beneficios de las plantas en relación con la colonización por hongos endófitos generalmente son inducidos en las etapas tempranas (Soliman et al., 2013), y en este 
trabajo se comprobó que este efecto perdura hasta la etapa de invernadero, a los 87 ddi en aquellas plantas que fueron inoculadas en semilla, y con aislados locales. En el presente estudio se reportó un alto porcentaje de colonización principalmente por parte del aislado local RV05 a los 28 ddi (Fig. 4A), y de las cepas RV01 y SL14 a los 45 ddi (Fig. 4B). Cuando es inoculado desde semilla, la colonización de $M$. anisopliae con su hospedero comúnmente inicia a los 7 ddi en los que debe competir con otros microorganismos en la rizosfera, y en ocasiones es forzado a actuar como un endófito oportunista (Barelli et al., 2018). En la colonización inicial del hospedero intervienen diversos factores, y se mantienen mientras exista un equilibrio entre los costos y los beneficios de la relación mutualista entre la planta y el HEE (Hiruma et al., 2016). Es evidente que ocurrió una interacción benéfica en las plantas de chile poblano inoculadas con las cepas RV01 y RV05, las cuales mostraron mayor desarrollo radicular y de la parte área de la planta, y, además, en ambos casos, la inoculación en semillas fue el mejor método para inducir estos efectos. Esta reportado en Arabidopsis thaliana que la interacción entre la hifa del hongo con las raíces es más estable que las relaciones con células de la epidermis, y solo promueve el crecimiento cuando la biodisponibilidad de nutrientes es baja, lo cual genera una respuesta en la planta (factores de transcripción) que favorecen el crecimiento del hongo dentro de la planta (Liberman y Benfey, 2016). De acuerdo con los resultados discutidos anteriormente, RV05 coloniza plantas de chile poblano de manera eficiente cuando es desinfectada y después sumergida en una solución de conidios, y esta persiste hasta los 121 ddi (Fig. 4).

\section{Conclusiones}

En este trabajo se comprobó experimentalmente la promoción de crecimiento vegetal hasta la etapa de invernadero en chile poblano, con la inoculación con aislados de HEE nativos de San Luis Potosí (RV01 y RV05). El resto de las cepas estudiadas no promovieron el crecimiento.

El mejor método de inoculación de HEE fue el de sumergir las semillas estériles en una solución de conidios (MI), incrementando el peso seco del tejido foliar, la producción de biomasa, la longitud de la raíz y con capacidad de mejorar las características funcionales del cultivo (tasa de asimilación neta, transpiración, $\phi_{\text {PSII }}$ y la qP) y el porcentaje de colonización. 
La inoculación con hongos endófitos entomopatógenos en semilla genera una respuesta fisiológica y promueve el crecimiento vegetal en plantas de chile poblano en invernadero

\section{$\underline{\text { Agradecimientos }}$}

Al Consejo Nacional de Ciencia y Tecnología por la beca de doctorado (Número de registro 257450) otorgada para el primer autor y al financiamiento recibido por parte del fondo de Apoyo a la investigación (FAI) de la Universidad Autónoma de San Luís Potosí con el proyecto: "Aplicación de hongos endófitos en biocontrol de plagas, fitopatógenos y como biofertilizante aplicado en cultivos agrícolas en San Luis Potosí, convenio C18-FAI-05-73.73.

\section{$\underline{\text { Referencias }}$}

Akello, J. \& Sikora, R. (2012). Systemic acropedal influence of endophyte seed treatment on Acyrthosiphon pisum and Aphis fabae offspring development and reproductive fitness. Biological Control, 61(3), 215-221. DOI: https://doi.org/10.1016/j.biocontrol.2012.02.007

Akutse, K.S., Maniania, N.K., Fiaboe, K.K.M., Van den Berg, J. \& Ekesi, S. (2013). Endophytic colonization of Vicia faba and Phaseolus vulgaris (Fabaceae) by fungal pathogens and their effects on the life-history parameters of Liriomyza huidobrensis (Diptera: Agromyzidae). Fungal Ecology, 1-9.

Bamisile, B.S., Dash C.K., Akutse, K.S., Keppanan, R., Afolabi, O.G., Hussain, M., Qasim, M. \& Wang, L. (2018). Prospects of endophytic fungal entomopathogens as biocontrol and plant growth promoting agents: An insight on how artificial inoculation methods affect endophytic colonization of host plants. Microbiological Research, 217, 34-50.

Behie, S.W., Moreira, C.C., Sementchoukova, I., Barelli, L., Zelisko, P.M. \& Bidochka, M.J. (2017). Carbon translocation from a plant to an insect-pathogenic endophytic fungus. Nature communications, 8(1), 1-5. DOI: 10.1038/ncomms14245

Buchanan, B.B., Gruissem, W. \& Jones, R.L. (2015). Biochemistry \& Molecular Biology of Plants. Second ed. NJ, USA: John Wiley \& Sons, Hoboken.

Castillo-López, D., Zhu-Salzman, K., Ek-Ramos, M.J. \& Sword, G.A. (2014). The entomopathogenic fungal endophytes Purpureocillium lilacinum (formerly Paecilomyces lilacinus) and Beauveria bassiana negatively affect cotton aphid reproduction under both greenhouse and field conditions. Planta, 9(8), e103891.

Centritto, M., Lauteri, M., Monteverdi, M.C. \& Serraj, R. (2009). Leaf gas exchange, carbon isotope discrimination, and grain yield in contrasting rice genotypes subjected to water deficits during the reproductive stage. Journal of Experimental Botany, 60, 2325-2339 
Cho, S. M., Kang, B.R., Han, S. H., Anderson, A. J., Park, J. Y., Lee, Y. H., Baik Ho Cho, K.Y. Yang, Ryu C.M., \& Young C.K. \& Kim, Y.C. (2008). 2R, 3R-butanediol, a bacterial volatile produced by Pseudomonas chlororaphis O6, is involved in induction of systemic tolerance to drought in Arabidopsis thaliana. Molecular Plant-Microbe Interactions, 21(8), 1067-1075.

Dogan, A., Erler, F., Erkan, M., Ates, A.O., Sabanci, H.S. \& Polat, E. (2016). Microbial-based production system: A novel approach for plant growth and pest and disease management in greenhouse-grown peppers (Capsicum annuum L.). Journal of Agricultural Science and Technology, 18(2), 371-386.

Dubey, A., Malla, M.A., Khan, F., Chowdhary, K., Yadav, S., Kumar, A., Sharm, S. Khare, P.K., \& Khan, M.L. (2019). Soil microbiome: a key player for conservation of soil health under changing climate under changing climate. Biodiversity and Conservation, 28(8-9), 24052429.

FAOSTAT (2017) www.faostat.fao.org (Revisado el 19 de abril del 2019).

Garcia, J.E., Posadas, J.B., Perticari, A. \& Lecuona, R.E. (2011). Metarhizium anisopliae (Metschnikoff) Sorokin promotes growth and has endophytic activity in tomato plants. Adv. Biol. Res, 5, 22-27.

García-Cristobal, J., García-Villaraco, A., Ramos, B., Gutiérrez-Mañero, J. \& Lucas, J. A. (2015). Priming of pathogenesis related-proteins and enzymes related to oxidative stress by plant growth promoting rhizobacteria on rice plants upon abiotic and biotic stress challenge. Journal of plant physiology, 188, 72-79. DOI: 10.1016/j.jplph.2015.09.011

Geisen, S., Kostenko, O., Cnossen, M.C., ten Hooven, F.C., Vreš, B., \& van der Putten, W.H. (2017). Seed and Root Endophytic Fungi in a Range Expanding and a Related Plant Species. Frontiers in microbiology, 8, 1-11.

Ghaffari, M.R., Mirzaei, M., Ghabooli, M., Khatabi, B., Wu, Y., Zabet-Moghaddam, M., Mohammadi-Nejad, G., Haynes, P.A., Hajirezaei, M.R., Sepehri, M. \& Hosseini-Salekdeh, G. (2018). Root endophytic fungus Piriformospora indica improves drought stress adaptation in barley by metabolic and proteomic reprogramming. Environmental and Experimental Botany, 157, 197-210. 
Gómez-Vidal, S., López-Llorca, L.V., Jansson, H.B. \& Salinas, J. (2006). Endophytic colonization of date palm (Phoenix dactylifera L.) leaves by entomopathogenic fungi. Micron, 37(7), 624-632.

Greenfield, M., Gómez-Jiménez, M.I., Ortiz, V., Vega, F.E., Kramer M. \& Parsa S. (2016). Beauveria bassiana and Metarhizium anisopliae endophytically colonize Cassava roots following soil drench inoculation. Biological Control, 95, 40-48. DOI: https://doi.org/10.1016/j.biocontrol.2016.01.002

Gurulingappa, P., Sword, G. A., Murdoch, G. \& Mcgee, P.A. (2010). Colonization of crop plants by fungal entomopathogens and their effects on two insect pests when in planta. Biological Control, 55(1), 34-41.

Hiruma, K., Gerlach, N., Bucher, M., Sacristan, S., Nakano, R.T., Hacquard, B.K., Kracher, B. Neumann, U., Ramírez, D., Bucher, M., O’Connell, R.J., \& Schulze-Lefert, P. (2016). Root Endophyte Colletotrichum tofieldiae confers plant fitness benefits that are phosphate status root endophyte Colletotrichum tofieldiae confers plant fitness benefits that are phosphate status dependent. Cell, 165, 464-474.

Hyde, K.D. \& Soytong, K. (2008). The fungal endophyte dilemma. Fungal Diversity, 33, 163-173.

Jaber, L.R. \& Enkerli, J. (2016). Fungal entomopathogens as endophytes: ¿can they promote plant growth? Biocontrol Science and Technology, 9, 544.

Jaber, L.R. \& Ownley, B.H. (2018). ¿Can we use entomopathogenic fungi as endophytes for dual biological control of insect pests and plant pathogens? Biological Control, 116, 36-45.

Joukhadar, I. \& Walker, S. (2020). Effect of Stand Reduction at Different Growth Stages on Yield of Paprika-Type Chile Pepper. Horticulturae, 6, 16.

Kalaji, H.M., Schansker, G., Ladle, R.J., Goltsev, V., Bosa, K., Allakhverdiev, S.I., Brestic, M., Bussotti, F., Calatayud, A., Dąbrowski, P., Elsheery, N.I., Ferroni, L., Guidi, L., Hogewoning, S.W., Jajoo, A., Misra, A.N., Nebauer, S.G., Pancaldi, S., Penella, C., Poli, D., Pollastrini, M., Romanowska, D., Zdzislawa, B., Rutkowska, B., Serôdio J, Suresh K., Szulc W, Tambussi, E., Yanniccari, M. \& Zivcak, M. (2014). Frequently asked questions about in vivo chlorophyll fluorescence: Practical issues. Photosynthesis Research, 122(2), $121-158$.

Khan, A.L, Shinwari, Z.K., Kim, Y.H., Waqas, M., Hamayun, M., Kamran, M. \& Lee, I.J. (2012). Role of endophyte Chaetomium globosum $1 \mathrm{k} 4$ in growth of Capsicum annuum by 
production of gibberellins and indole acetic acid. Pakistan Journal of Botany, 44(5), 16011607.

Khan, A.R., Ullah, I., Waqas, M., Shahzad, R., Hong, S.J., Park, G.S., Park, G. S., Jung B. K., Lee I.J. \& Shin, J.H. (2015). Plant growth-promoting potential of endophytic fungi isolated from Solanum nigrum leaves. World Journal of Microbiology and Biotechnology, 31(9), 14611466.

Kramer, D.M. \& Evans, J.R. (2011) The importance of energy balance in improving photosynthetic productivity. Plant Physiology, 155,70-78.

Krell, V., Unger, S., Jakobs-Schoenwandt, D. \& Patel, A.V. (2018). Endophytic Metarhizium brunneum mitigates nutrient deficits in potato and improves plant productivity and vitality. Fungal Ecology, 34, 43-49.

Lesk, C., Rowhani, P. \& Ramankutty, N. (2016). Influence of extreme weather disasters on global crop production. Nature, 529(7584), 84-87. DOI: https://doi.org/10.1038/nature16467

Li, W., Zhang, S. \& Shan, L. (2007). Responsibility of non-stomatal limitations for the reduction of photosynthesis-response of photosynthesis and antioxidant enzyme characteristics in alfalfa (Medicago sativa L.) seedlings to water stress and rehydration. Frontiers of Agriculture in China, 1(3), 255-264.

Liberman, L.M. \& Benfey, P. N. (2016). A Friend in Need (of Nutrients) Is a … Cell, 165(2), 269271. DOI: https://doi.org/10.1016/j.cell.2016.03.036

Mantzoukas, S., Chondrogiannis,C. \& Grammatikopoulos, G. (2015). Effects of three endophytic entomopathogens on sweet sorghum and on the larvae of the stalk borer Sesamia nonagrioides. Entomologia Experimentalis et Applicata, 154(1), 78-87.

Mckinnon, A.C., Saari, S., Nicolai, M.E.M., Raad, M. \& Glare, T.R. (2016). Beauveria bassiana as an endophyte: a critical review on associated methodology and biocontrol potential. BioControl, 62(1), 1-17.

Orellana, C. \& León, E. (2011). Evaluación de la Producción del Cultivo Hidropónico de 3 Variedades de Pimiento (Capsicum annuum L.) Bajo Invernadero en la Solución Nutritiva La Molina. Cuenca, Ecuador. 119 p.

Ortiz-Espinoza, E., Villegas-Rodríguez, F., Delgado-Sánchez, P., Hernández-Arteaga, L.E. Del S., Marín, J.S., Ramírez-Tobías, H.M. \& Villarreal-Guerrero, F. (2019). Inoculation with 
La inoculación con hongos endófitos entomopatógenos en semilla genera una respuesta fisiológica y promueve el crecimiento vegetal en plantas de chile poblano en invernadero

entomopathogenic fungi reduces seed contamination, improves seed germination and growth of chilli seedlings. African Journal of Agricultural Research, 14(32), 1463-1471.

Ownley, B.H., Griffin, M.R., Klingeman, W.E., Gwinn, K.D., Moulton, J.K. \& Pereira, R.M. (2008). Beauveria bassiana: Endophytic colonization and plant disease control. Journal of Invertebrate Pathology, 98(3), 267-270. DOI: 10.1016/j.jip.2008.01.010

Parsa, S., Ortiz, V. \& Vega, F.E. (2013). Establishing Fungal Entomopathogens as Endophytes: Towards Endophytic Biological Control Establishing Fungal Entomopathogens as Endophytes: Towards Endophytic. Journal of Visualized Experiment, (76), e50360.

Paul, N.C., Deng, J.X., Lee, J.H. \& Yu, S.H. (2013). New records of endophytic Paecilomyces inflatus and Bionectria ochroleuca from Chili Pepper Plants in Korea. Mycobiology, 41(1), $18-24$.

Quesada-Moraga, E., Muñoz-Ledesma, F.J. \& Santiago-Álvarez, C. (2009). Systemic Protection of Papaver somniferum L. against Iraella luteipes (Hymenoptera: Cynipidae) by an Endophytic Strain of Beauveria bassiana (Ascomycota: Hypocreales). Environmental Entomology, 38(3), 723-730.

Raya-Díaz, S., Sánchez-Rodríguez, A.R., Segura-Fernández, J.M., del Campillo, M.d.C. \& Quesada-Moraga, E. (2017). Entomopathogenic fungi-based mechanisms for improved Fe nutrition in sorghum plants grown on calcareous substrates. PLoS One, 12 e0185903.

Rios-Velasco, C., Pérez-Corral, D. A., Salas-Marina, M. Á., Berlanga-Reyes, D.I., Ornelas-Paz, J. J., Acosta Muñiz, C. H., Cambero-Campos J. \& Jacobo-Cuellar, J.L. (2014). Pathogenicity of the Hypocreales fungi Beauveria bassiana and Metarhizium anisopliae against insect pests of tomato. Southwestern Entomologist, 39(4), 739-750.

Rothen, C., Miranda, V., Aranda-Rickert, A., Fracchia, S. \& Rodríguez, M.A. (2017). Characterization of dark septate endophyte fungi associated with cultivated soybean at two growth stages. Applied Soil Ecology, 120, 62-69.

Rozpądek, P., Wężowicz, K., Nosek, M., Ważny, R., Tokarz, K., Lembicz, M., Miszalski, Z. \& Turnau, K. (2015). The fungal endophyte Epichloë typhina improves photosynthesis efficiency of its host orchard grass (Dactylis glomerata). Planta, 242(4), 1025-1035. DOI: https://doi.org/10.1007/s00425-015-2337-x

Samaniego-Gámez, B.Y., Garruña, R., Tun-Suárez, J.M., Kantun-Can, J., Reyes-Ramírez, A., y Cervantes-Díaz, L. (2016). Bacillus spp. inoculation improves photosystem II efficiency 
and enhances photosynthesis in pepper plants. Chilean Journal of Agricultural Research, 76(4), 409-416.

Sasan, R.K. \& Bidochka, M.J., (2012). The insect-pathogenic fungus Metarhizium robertsii (Clavicipitaceae) is also an endophyte that stimulates plant root development. Am. J. Bot. 99, 101-107.

Sauder, D. C. \& DeMars, C.E. (2019). An updated recommendation for multiple comparisons. Advances in Methods and Practices in Psychological Science, 2(1), 26-44.

Sepúlveda, M., Vargas, M., Gerding, M., Ceballos, R. \& Oyarzúa, P. (2016). Molecular, morphological and pathogenic characterization of six strains of Metarhizium spp.(Deuteromycotina: Hyphomycetes) for the control of Aegorhinus superciliosus (Coleoptera: Curculionidae). Chilean Journal of Agricultural Research, 76(1), 77-83. DOI: http://dx.doi.org/10.4067/S0718-58392016000100011

Soliman, S.S.M., Trobacher, C.P., Tsao, R., Greenwood, J.S. \& Raizada, M.N. (2013). A fungal endophyte induces transcription of genes encoding a redundant fungicide pathway in its host plant. BMC Plant Biology, 13(1), 93.

Tall, S. \& Meyling, N.V. (2018). Probiotics for plants? growth promotion by the entomopathogenic fungus Beauveria bassiana depends on nutrient availability. Microbial Ecology, 76(4), 1002-1008. DOI: 10.1007/s00248-018-1180-6

Vidal, S. \& Jaber, L.R. (2015). Entomopathogenic fungi as endophytes: Plant-endophyte-herbivore interactions and prospects for use in biological control. Current Science, 109(1), 46-54.

Villegas-Rodríguez, F., Marín-Sánchez, J. \& Torres-Castillo J.A. (2014). Management of Bactericera cockerelli (Sulc) (Hemiptera: Triozidae) in Greenhouses with Entomopathogenic Fungi (Hypocreales). Southwestern Entomologist, 39(3), 613.

Villegas-Rodríguez, F., Casas-Flores, J. S., Tamayo-Mejía, F., Aguilar-Medel, S., Díaz-Gómez, O. \& Monreal-Vargas, C.T. (2017). Activity of two entomopathogenic fungi, molecularly identified, on Bactericera cockerelli. Revista Colombiana de Entomología, 43(1), 27-33. 